\title{
Gerenciamento de resultados por meio da perda estimada de créditos em bancos brasileiros e luso-espanhóis
}

\author{
Earnings management with the estimated loss of credits in Brazilian and Portuguese- \\ Spanish banks
}

Gestión de resultados por medio de la pérdida estimada de créditos en bancos brasileños y luso-españoles

\section{Carlos Alberto Martins Silva}

Mestre em Ciências Contábeis PMIICC-UnB-UFPB-UFRN

Contador na Brasil Pharma

Endereço: Campus Universitário Darcy Ribeiro - Prédio da FACE - Asa Norte

CEP: 70910-900 - Brasília/DF - Brasil

E-mail: calbmartins@gmail.com

Telefone: (61) 3359-5541

\section{Jorge Katsumi Niyama}

Doutor em Contabilidade pela FEA/USP com Pós-doutorado pelas Universidades de Otago

(Nova Zelândia), Universidade de Coimbra (Portugal) e IUL/ISCTE (Portugal)

Professor do Programa de Pós-Graduação da Universidade de Brasília (UnB)

Endereço: SQN 115 - Bloco I - apt.606

CEP: 70072-090- Brasília/DF - Brasil

E-mail: jorgekatsumi@gmail.com

Telefone - 06131070812

\section{Jomar Miranda Rodrigues}

Doutor em Ciências Contábeis no PMIICC-UnB-UFPB-UFRN.

Professor do Departamento de Ciências Contábeis e Atuariais da Universidade de Brasília (UnB)

Endereço: Campus Universitário Darcy Ribeiro

Prédio da FACE - Sala BT2 47/7 - Asa Norte

CEP: 70910-900 - Brasília/DF - Brasil

E-mail: jomar@unb.br

Telefone: (61) 3107-0795

\section{Isabel Maria Estima Costa Lourenço}

Doutor em Gestão na Universidade ISCTE-IUL

Professor do ISCTE-IUL, Portugal

Endereço: Avenida das Forças Armadas,

CEP: 1649-026 - Lisboa - Portugal

E-mail: isabel.lourenco@iscte-iul.pt

Telefone: (351) 962123821

Artigo recebido em 06/04/2017. Revisado por pares em 25/09/2018. Reformulado em 20/03/2019. Recomendado para publicação em 20/03/2019 por Carlos Eduardo Facin Lavarda Editor-Chefe). Publicado em 10/04/2019. 


\title{
Resumo
}

$\mathrm{O}$ estudo avaliou a existência de gerenciamento de resultado nas instituições financeiras brasileiras e luso-espanholas utilizando as estimativas de perda sobre operações de crédito. As estimativas sobre as operações de crédito constituem a principal estimativa das instituições financeiras, dadas as características das instituições, o gerenciamento de resultado no sistema bancário é especialmente delicado pelos riscos que as instituições financeiras estão expostas e potenciais impactos da efetivação dos riscos de não realização dos créditos. A literatura internacional evidencia que a administração de bancos faz uso de seu poder discricionário na constituição de estimativas de perda sobre as operações de crédito com o objetivo de gerenciar resultados. Neste sentido, a pesquisa voltou-se para análise das acumulações discricionárias em amostra de instituições financeiras brasileiras e luso-espanholas no período de junho de 2009 a dezembro de 2014. Como resultado, foi possível observar que as instituições financeiras brasileiras e luso-espanholas utilizam as despesas com provisões sobre as operações de créditos para gerenciar resultados.

Palavras-Chave: Gerenciamento de resultados; Instituições financeiras; Estimativa de perda de créditos; Operações de crédito

\begin{abstract}
The search evaluated the existence of earnings management in Brazilian and PortugueseSpanish financial institutions using estimates of loss on credit operations. Estimates of credit operations (loans) are the main estimate of financial institutions, given the characteristics of institutions, the management of results in the banking system is especially sensitive to the risks that financial institutions are exposed and potential impacts of the effectiveness of those risks. The international literature shows that banks manage your earnings with discretion in the constitution of loss estimates on loans. In this sense, the research turned to the analysis of discretionary accumulations in a sample of Brazilian and Portuguese-Spanish financial institutions from June 2009 to December 2014. As a result, it was possible to observe that Brazilian and Portuguese-Spanish financial institutions use expenses with provisions on loan operations to earnings management.
\end{abstract}

Keywords: Earnings management; Banks; Estimate of loss of credits; Loans

\section{Resumen}

El estudio evaluó la existencia de gestión de resultados en las instituciones financieras brasileñas y luso-españolas utilizando las estimaciones de pérdida sobre operaciones de crédito. Las estimaciones sobre las operaciones de crédito constituyen la principal estimación de las instituciones financieras, dadas las características de las instituciones, la gestión de resultados en el sistema bancario es especialmente delicada por los riesgos que las instituciones financieras están expuestas y potenciales impactos de la efectividad de los riesgos de no realización de los riesgos créditos. La literatura internacional evidencia que la administración de bancos hace uso de su poder discrecional en la constitución de estimaciones de pérdida sobre las operaciones de crédito con el objetivo de gestionar resultados. En este sentido, la investigación se volvió para análisis de las acumulaciones discrecionales en muestra de instituciones financieras brasileñas y luso-españolas en el periodo de junio de 2009 a diciembre de 2014. Como resultado, fue posible observar que las instituciones financieras brasileñas y luso-españolas utilizan los gastos de provisión sobre las operaciones de créditos para gestionar los resultados.

Palabras Clave: Gestión de resultados; Instituciones financieras; Estimación de pérdida de créditos; Operaciones de crédito 


\section{Introdução}

Os bancos têm papel importante para o funcionamento da economia e têm seu desempenho avaliado por meio de informações contábeis que envolvem julgamento de seus responsáveis e preparadores, particularmente nos itens objeto de estimativas. Nas instituições financeiras, as principais estimativas estão relacionadas as perdas de operações de créditos, empréstimos e operações análogas.

Por sua natureza, as estimativas contábeis têm parcela significativa de emprego de julgamento profissional, o que propicia a oportunidade para a prática do gerenciamento de resultados, na esteira da utilização de alternativas discricionárias na escolha de critérios de reconhecimento, classificação e mensuração.

O gerenciamento dos resultados contábeis é uma expressão utilizada para designar um conjunto de práticas adotadas por gestores e contadores com o intuito de obter os resultados contábeis desejados, os quais, normalmente, decorrem de manipulações que estão dentro dos limites legais (RODRIGUES, 2007).

A dificuldade de identificação do gerenciamento de resultados pelos usuários, especificamente naqueles casos que envolvem discricionariedade sobre as estimativas, revelase um estímulo para o emprego dessa prática por parte dos elaboradores das demonstrações. Este é possível pela aplicação de julgamento envolvendo certo grau de subjetividade nas premissas possíveis para o reconhecimento e a mensuração contábil. Assim, relacionando-se à subjetividade e à flexibilidade no julgamento, é possível identificar que interesses particulares podem ser determinantes no conteúdo das demonstrações financeiras e do resultado por elas apresentado.

Isso decorre da impossibilidade e, até, da inconveniência, das normas contábeis abrangerem todas as possíveis situações operacionalizadas pelos negócios. Assim, os padrões contábeis não conseguem limitar a aplicação de julgamentos e estimativas nas escolhas entre diferentes procedimentos alternativos. Têm-se, com isso, o espaço para o gestor aplicar suas estimativas em aspectos como mensuração com métodos mais favoráveis.

As demonstrações financeiras têm diversos usuários, e, em relação às instituições financeiras, os reguladores observam importantes aspectos para o sistema financeiro com base em tais informações. Entre os parâmetros regulamentares, destaca-se a obrigação da manutenção dos níveis mínimos de capital, aspecto fundamental que busca garantir: a estrutura de captação de recursos que considerem riscos atrelados à instituição e ao sistema financeiro; e a solidez de sua estrutura patrimonial, além dos resultados obtidos. Assim, o gerenciamento de resultados é uma prática possível no alcance de tais objetivos, e a modalidade conhecida como suavização dos resultados (income smoothing) é procedimento de interesse para as instituições financeiras em relação ao desempenho esperado.

Considerando esse contexto, este estudo teve por norte o gerenciamento de resultados por meio das perdas estimadas, com foco nos sistemas bancários brasileiro e luso-espanhol. A escolha desses mercados se dá em função da relação histórica entre os países e a possível influência mútua, combinada com a adoção de padrões contábeis distintos. Segundo Freyre (2000), a relação entre Brasil e Portugal é relevante desde o início, e as características de diversidade e de mobilidade do Brasil são desdobramentos do legado português a sua anterior colônia. Em relação a Portugal, não há como afastar a relação íntima com a Espanha - país este que guarda intensas relações históricas e econômicas com Portugal.

A perspectiva de análise das três nações considera a forte relação histórica. Dessa forma, o relacionamento luso-espanhol ao longo dos séculos conviveu com teorias pró-iberismo e antiiberistas, com discussões em relação ao desenvolvimento econômico no contexto de unificação e em separado. Ou seja, considerando que a história lusa se confunde com a espanhola, a análise aqui se fez de modo conjunto - instituições financeiras portuguesas e espanholas. 
Diante do exposto, a pesquisa teve por objetivo verificar a existência de evidências de que as instituições financeiras brasileiras e luso-espanholas fazem uso da contabilização da estimativa de perda para fins de gerenciamento de resultados, além de avaliar as semelhanças e diferenças dessa prática nos dois ambientes - Brasil e Portugal/Espanha.

A pesquisa justifica-se porque poucos estudos avaliaram o gerenciamento de resultado no contexto de sistemas financeiros diferentes, existindo pouca literatura sistematizada com esse tipo de foco, que permite identificar não só as influências culturais como de diferentes padrões contábeis em relação a essa prática.

A pesquisa tem abordagem empírica, verificando se o componente discricionário das despesas com provisão para créditos de liquidação duvidosa é utilizado para gerenciamento de resultado. Para esse fim, são considerados os dados de 30 instituições financeiras brasileiras e 31 luso-espanholas, considerando o período de 2009 a 2014.

\section{Referencial Teórico}

\subsection{Gerenciamento de Resultados}

O gerenciamento de resultados é uma prática que faz uso de um método contábil específico para alterar números, conforme Wong (2011). Segundo o autor, o gerenciamento de resultados pode ser aplicado quando da manipulação operacional ou pela contabilidade. A manipulação operacional - também chamada de gerenciamento de resultados reais - afeta o tempo ou a seleção de eventos de negócios reais. A definição utilizada com frequência na literatura é a dada por Healy e Whalen (1999, p. 368):

Gerenciamento de resultados ocorre quando os gerentes usam julgamento na informação financeira e na estruturação de operações para alterar relatórios financeiros, buscando enganar interessadas sobre o desempenho da empresa ou de influenciar os resultados contratuais que dependem de saldos contábeis reportados.

Para Schipper (1989), o gerenciamento de resultados representa uma intervenção deliberada no processo de elaboração das demonstrações financeiras, com a intenção de obtenção de benefício, oposto ao processo neutro de reporte dos resultados contábeis. No que concerne à literatura nacional, Martinez (2001) destaca que o gerenciamento de resultados se dá dentro dos limites que prescreve a legislação contábil, buscando os pontos em que as normas facultam certa discricionariedade ao gestor.

O gerenciamento de resultados pode ser segregado em modalidades diferenciadas, que refletem os objetivos e incentivos para a aplicação dos procedimentos de gerenciamento de resultados, de acordo com Burgstahler e Dichev (1997):

- Bump Up: para as empresas que possuem ações em bolsa, os gestores têm incentivos para fazer com que a meta seja ultrapassada e, nesses casos, fazem uso de alguma forma de gerenciamento de resultados para melhorar seu desempenho;

- Cookie-Jar Accounting: modalidade na qual a entidade, com informações prévias de que os resultados devem ultrapassar um determinado montante esperado, influencia os gestores a reduzir os resultados correntes, para aumentar o resultado quando esse estiver abaixo do esperado;

- Income Smoothing: modalidade mais encontrada nas pesquisas empíricas, se baseia na premissa de que a dispersão dos resultados é entendida pelos usuários como medida de risco. Assim, menor variação tende a atrair mais investidores, bem como facilitar a captação de recursos a custos mais baixos. A percepção do mercado pode incentivar os gestores a tornar o resultado menos volátil, suavizando o seu fluxo de crescimento;

- Big Bath Accounting: modalidade de aumento dos resultados futuros pela antecipação de despesas que não precisariam ser reconhecidas no período corrente. 
Nas instituições financeiras, o comportamento relativo ao gerenciamento de gerenciamento, geralmente, está ligado a Income Smoothing, assim buscando reduzir a variação dos resultados entre os exercícios.

Para Dechow e Skinner (2000), a identificação de práticas de suavização de resultados pode ser algo difícil em função do regime de competência apresentar resultados com menos flutuações relativamente ao padrão observado no regime de caixa. Assim, eventualmente, é difícil distinguir a suavização decorrente de práticas de gerenciamento de resultados provenientes da operação natural do regime de competência e do exercício legitimo da discricionariedade, que objetivam a apresentação de informações que sejam úteis para os investidores avaliarem o desempenho econômico e a capacidade futura de geração de caixa das empresas. Conforme Spohr (2005), é difícil identificar se o gerenciamento de resultados objetiva ser enganoso.

Por fim, as normas contábeis não abrangem todas as possíveis situações operacionalizadas pelos negócios e, portanto, os padrões contábeis não conseguem limitar a aplicação de estimativas nas escolhas entre diferentes procedimentos alternativos. Assim, há espaço para o gestor aplicar suas estimativas em aspectos como mensuração utilizando métodos mais favoráveis. A principal motivação por trás de gerenciamento de resultados é alcançar um resultado desejado em um período, em vez de apresentar com precisão o valor dos ativos e passivos ou os resultados das operações (WONG, 2011).

\subsection{Gerenciamento de Resultados em Instituições Financeiras}

Para Cornett, McNutt e Theranian (2009), o estudo do gerenciamento de resultados no sistema financeiro é especialmente delicado, considerando os impactos que os mais variados tipos de problemas em bancos podem acarretar no comportamento da economia. Cheng, Warfield e Ye (2009) ressaltam que os efeitos de crises aumentam a relevância de se investigar a prática do gerenciamento de resultados no segmento bancário, tendo em vista a relevância dos bancos na economia.

As instituições financeiras têm como principal estimativa a perda estimada de operações de crédito (empréstimos). Conforme Cohen et al. (2014), os reguladores bancários visualizam as perdas estimadas (ou ainda denominadas provisões) com empréstimos como um tipo de capital que pode ser utilizado para absorver prejuízos. Um equilíbrio maior nas perdas potenciais de empréstimo permite ao banco absorver maiores perdas inesperadas. Entretanto, com base nos aspectos discricionários envolvidos, a mensuração da estimativa pode representar uma possibilidade de gerenciamento de resultados. Ahmed, Takeda e Thomas (1999) corroboram essa perspectiva ao afirmarem que as estimativas de perdas são, em realidade, as grandes acumulações para os bancos comerciais e, portanto, têm impacto significativo sobre os resultados e para o capital dos bancos.

Cohen et al. (2014) afirmam que os bancos utilizam as perdas estimadas com empréstimos para gerir resultado e os níveis de capital. O autor constata, ainda, que acumulações discricionárias são negativamente relacionadas ao capital e que os administradores aumentam estimativas discricionárias para perdas com empréstimos quando esperam fluxos de caixa futuros. Entre outros aspectos, constata que os bancos públicos são mais propensos a utilizar as perdas estimadas para eliminar pequenas diminuições de lucros.

Dada a sua natureza, um aspecto importante para os bancos é a regulamentação, particularmente a exigência de relação de capital mínimo, buscando reduzir a probabilidade de quebra dessas instituições. Quando os bancos estão a atingir baixos índices de capital, há um aumento na vigilância por parte das autoridades e, em casos graves, há intervenções nas operações de bancos com o capital inadequado (BEATTY; CHAMBERLAIN; MAGLIOLO, 1995). 
No trabalho de Beaver e Engel (1996), são listadas quatro motivações para a utilização discricionária das perdas estimadas, quais sejam: regulamentação; relatórios financeiros; fatores fiscais e sinalização ao mercado. Além dos benefícios com income smoothing que também é um incentivo para manipular as perdas estimadas (CHENG; WARFIELD; YE, 2009; AHMED; TAKEDA; THOMAS, 1999).

Estudos sobre gerenciamento de resultados em instituições financeiras confirmam a utilização da perda estimada como forma de gerenciar resultado. O estudo de Shrieves e Dahl (2003), por exemplo, avaliou a utilização de discricionariedade contábil nas instituições financeiras do Japão no período entre 1989 e 1996. A pesquisa confirmou a hipótese de que bancos japoneses utilizaram práticas de gerenciamento de resultados como forma de reagir ao cenário adverso da vigência do Acordo da Basileia (primeiro ano do estudo - 1989) que, conforme os autores, ameaçava reduzir o acesso dos bancos japoneses ao mercado internacional em decorrência da deterioração da qualidade de seus ativos.

Pinho e Martins (2009) avaliaram o comportamento discricionário na estimava de perda nos bancos portugueses, objetivando avaliar o impacto do ambiente regulatório das instituições financeiras nas práticas de provisionamento discricionário. Para isso, desenvolveram um modelo que estrutura a dinâmica da política para as classes de provisões genéricas e provisões específicas. O modelo foi testado usando um banco de dados abrangente de todas as instituições financeiras autorizadas a operar em Portugal entre 1990 a 2000, constatando a existência de gerenciamento por meio da utilização do componente discricionário nas provisões, compensando o total das provisões quando havia a necessidade de aumento por requisitos regulatórios.

Os resultados de Ahmed, Takeda e Thomas (1999) confirmaram a hipótese de gerenciamento de capital e refutaram a hipótese de gerenciamento de resultados. As variáveis resultado antes do imposto de renda e despesa com perdas estimadas de crédito tiveram relação positiva, mas não foram significativas com as despesas com perdas estimadas na regulamentação bancária anterior e negativa na atualizada, naquele momento. A pesquisa encontrou relação positiva entre a qualidade dos créditos e as despesas com perdas estimadas de crédito.

Como resultado da pesquisa, Beatty, Chamberlain e Magliolo (1995) obtiveram evidências das perdas estimadas, dos créditos baixados como prejuízo para gerenciar o capital regulatório.

Segundo Cohen et al. (2014), o gerenciamento de resultados em bancos geralmente é medido pela propensão para estimar perdas com empréstimos, confirmando a ótica de principal estimativa das instituições financeiras.

\subsection{Aspectos Regulatórios Relativos à perda estimada (ou ainda denominada PCLD) nos Mercados Financeiros Brasileiro, Português e Espanhol}

O Banco de Portugal exerce a função de supervisor prudencial das instituições de crédito, das sociedades financeiras e das instituições de pagamento em funcionamento no país, com vistas a assegurar a estabilidade, eficiência e solidez do sistema financeiro, o cumprimento de regras de conduta e de prestação de informação aos clientes bancários, bem como garantir a segurança dos depósitos e dos depositantes e a proteção dos interesses dos clientes.

O Decreto-Lei $n^{\circ} 158$, de 13 de julho de 2009, aprovou o Sistema de Normalização Contabilística (SNC), passando a exigir a aplicação das normas internacionais de contabilidade para entidades que tenham negociação de valores mobiliários. O Aviso do Banco de Portugal $\mathrm{n}^{\mathrm{o}} 01$, de 21 de fevereiro de 2005, determina que se apliquem as normas internacionais de contabilidade na elaboração das demonstrações financeiras, quer em base individual, quer em base consolidada, para determinadas instituições financeiras, sendo que, em cada momento da 
adoção das normas, o normativo requer que, na elaboração das demonstrações financeiras em base individual, sejam observadas orientações que não necessariamente estejam previstas nas normas emitidas pelo International Accounting Standards Board (IASB).

A Carta Circular $n^{\circ}$ 02, de 26 de abril de 2014, trata dos critérios na mensuração da imparidade da carteira de crédito e respectivas divulgações para as instituições financeiras portuguesas, que constituem um referencial mínimo para o tratamento contábil de operações específicas ou cumprimento de níveis mínimos de provisionamento. No documento, são incorporadas orientações quanto à metodologia de cálculo da imparidade da carteira de crédito, considerando: identificação dos indícios de imparidade; exposição individualmente significativa; exposições analisadas individualmente, exposições analisadas coletivamente; julgamentos, pressupostos e premissas; documentação (formalização) e divulgações.

No que se refere às instituições financeiras espanholas, o Regulamento $\mathrm{n}^{\mathrm{o}} 1.606$, de 19 de julho de 2002, introduziu o uso obrigatório das normas internacionais na União Europeia (UE), incluindo o setor financeiro. Na Espanha, a autoridade bancária é o Banco da Espanha (BDE), semelhante à estrutura portuguesa e à brasileira, sendo o responsável pela supervisão e regulação, incluindo os aspectos contábeis, das instituições financeiras. A Circular ${ }^{\circ}$ 04, de 22 de dezembro de 2004, adapta a regulamentação ao setor financeiro para as normas editadas pelo IASB, estabelecendo a aplicação reservada às demonstrações financeiras consolidadas. $\mathrm{O}$ Banco da Espanha, com base na sua experiência e nas informações sobre o setor bancário espanhol, estimou percentuais mínimos de cobertura, descritos na Circular $n^{0}$ 04/2004. Os percentuais de cobertura incluídos levam em conta o valor do dinheiro no tempo. As entidades devem aplicar, no mínimo, esses percentuais na estimativa de subsídios específicos para avaliação de perdas coletivas de transações registradas em nome de residentes espanhóis e em entidades subsidiárias estrangeiras. $\mathrm{O}$ Banco da Espanha atualiza regularmente essas estimativas, de acordo com a evolução dos dados do setor, por meio da revisão da Circular.

No Brasil, as perdas estimadas (ou ainda denominadas provisões para créditos de liquidação duvidosa) são constituídas com base na classificação das operações de créditos por níveis de risco, de acordo com os critérios definidos pela Resolução $\mathrm{n}^{\circ} 2.682$, de 22 de dezembro de 1999, do Conselho Monetário Nacional (CMN), com vigência a partir de março de 2000. Conforme Niyama e Gomes (2012), essa Resolução foi editada com a finalidade de harmonizar a regulamentação local às normas e aos padrões contábeis no âmbito do Mercosul e adequá-las à evolução e à sofísticação do mercado financeiro, bem como às mudanças no perfil de crédito das operações.

A partir da Resolução $\mathrm{CMN}^{0}$ 3.786, de 24 de setembro de 2009, as instituições financeiras passaram a apresentar demonstrações financeiras com bases de preparação diferenciadas, uma com as práticas aprovadas pelo $\mathrm{CMN}$ e outra com base nas práticas contábeis internacionais. Assim, as instituições financeiras e demais instituições autorizadas a funcionar pelo Banco Central do Brasil (BCB) utilizam em suas demonstrações financeiras, no contexto regulatório, o conceito de perda esperada, utilizando os critérios de constituição de perdas estimadas (ou PCLD) de acordo com a Resolução CMN n ${ }^{0}$ 2.682/1999; e, para as demonstrações financeiras no padrão internacional, fazem uso das premissas dispostas no IAS 39 , que emprega os conceitos de perda incorrida. A presente pesquisa utiliza os dados e analisa os resultados das provisões das demonstrações financeiras com as práticas regulatórias.

\subsection{Perdas de ativos estimados pelos critérios regulatórios e pelas normais internacionais - IFRS 9}

As instituições financeiras no Brasil apresentam demonstrações financeiras considerando as práticas contábeis determinadas pelo padrão regulatório e demonstrações financeiras de acordo com as normais internacionais. A partir de $1^{\circ}$ de janeiro de 2018, passou 
a vigorar as regras do IFRS 9, que dentre outros aspectos estabelece aspectos para mensuração de perdas de ativos financeiros, no Brasil vigorando por meio do Pronunciamento Técnico CPC 48. As instituições financeiras, entidades reguladas, aplicam em suas demonstrações financeiras (regulatórias) apenas as normais ratificadas pelo regulador. Isso posto, demonstrações financeiras baseadas nas normais internacionais, e baseadas na atual norma regulamentar possuem estimativas em critérios com conceitos que diferem em sua construção, dessa forma, mensurando estimativas diferentes para as perdas com créditos.

As estimativas efetuadas no modelo regulatório, possuem como característica a estimação de perda para créditos com classificação de risco por níveis, considerando os critérios de mensuração estipulada pelo regulador. Nesse sentido, as normais internacionais (IFRS 9) se baseiam em premissas de perda esperada, considerando o fluxo de caixa contratual que são devidos a instituição financeira descontados a taxa de juros efetiva.

Conforme Sayed et al. (2013), os critérios estabelecidos para o cálculo da estimativa de perda devem considerar as perdas durante toda a vida do ativo. Desse modo, devendo ser incluído no cálculo dos fluxos estimados: aspectos contratuais previstos, custos transacionais e perdas esperadas durante a vida do crédito. Ainda segundo a pesquisa, o efeito da transição para o IFRS 9 seria mais relevante no primeiro período de adoção, para os períodos seguintes as estimativas de perda se acomodariam em patamares mais estáveis. A pesquisa ainda demonstra que os resultados da transição para o IFRS 9 tem efeito diferente nas estimativas de perda entre as instituições financeiras.

Na pesquisa de Ferreira et al. (2018), foi abordado os critérios estabelecidos pelas normas para mensuração das estimativas de perda, realizando uma análise entre os aspectos descritos na norma regulatória nacional brasileira e a internacional, a pesquisa descreve ainda que o IFRS 9 está alinhado com os requerimentos de regulação bancária internacionais.

Em contraponto, a norma que foi substituída (IAS 39), teve em Silva e Robles Junior (2018) uma análise que descreve o maior resultado das instituições financeiras utilizando os critérios estabelecidos por essa norma em relação a norma do regulador, a norma se caracteriza por mensuração baseada em premissa de perda incorrida. A referida pesquisa não abordou os efeitos oriundos da implementação do IFRS 9 para instituições financeiras.

\section{Metodologia}

Os estudos sobre gerenciamento de resultados abordam o problema, de forma geral, por meio de análises do fluxo de caixa e análise de accruals. Conforme Beneish (2001), a partir da década de 1980, os estudos sobre gerenciamento de resultados concentraram-se nos accruals. Um dos motivos seriam as estimativas possibilitadas pelas práticas contábeis; o autor considera mais provável gerenciamento de resultados por meio de accruals.

Os estudos de gerenciamento de resultados em instituições financeiras têm maior concentração na análise das despesas com perdas estimadas. Isso porque, segundo Beaver e Engel (1996) e Kanagaretnam, Lobo e Mathieu (2001), são os maiores accruals dos bancos e, dessa forma, são meios relevantes para gerenciamento de resultados.

O presente estudo aborda o gerenciamento de resultados por meio da análise de accruals, considerando que as despesas com perdas estimadas (ou PCLD, denominação ainda utilizada no contexto regulatório) são as principais estimativas dos bancos. Para a estruturação do modelo, foram considerados os aspectos constantes nas pesquisas sobre o tema. Kanagaretnam, Lobo e Mathieu (2001), a respeito de perdas estimadas e suavização de resultados em bancos, observaram que a preocupação dos gestores com a manutenção do emprego cria um incentivo para que estes suavizem resultados. Na pesquisa, os autores perceberam que bancos com desempenho corrente ruim e bancos com expectativa de bom desempenho futuro "emprestaram" resultados de períodos futuros, reduzindo provisão corrente. 
Para os bancos com bom desempenho corrente e expectativa de desempenho futuro ruim, houve prática de postergar lucros para períodos futuros, por meio do aumento da perda estimada e consequente redução do lucro corrente.

Estudos que avaliariam o uso das provisões para perdas no gerenciamento de resultados nos bancos apresentam exemplos de dois tipos de procedimento - modelos de um e de dois estágios - e a escolha depende dos objetivos dos pesquisadores em cada pesquisa em particular. Ahmed, Takeda e Thomas (1999), Shrieves e Dahl (2003) e Goulart (2007), por exemplo, adotaram modelos de um estágio em suas investigações. Nos trabalhos de Beaver e Engel (1996), Kanagaretnam, Lobo e Mathieu (2001), Zendersky (2005), Marcondes (2008), Cheng, Warfield e Ye (2011) e Dantas et al. (2013), entre outros, utilizaram modelos de dois estágios nas pesquisas.

Tendo em vista os aspectos teóricos e a revisão de literatura sobre o tema, são formuladas as seguintes hipóteses de pesquisa, a serem testadas empiricamente:

$\boldsymbol{H}_{1 \boldsymbol{A}}$ : As instituições financeiras brasileiras adotam a prática de gerenciamento de resultados por meio das despesas com perdas estimadas (ou provisão para créditos de liquidação duvidosa).

$\boldsymbol{H}_{1 \boldsymbol{B}}$ : As instituições financeiras luso-espanholas adotam a prática de gerenciamento de resultados por meio das perdas estimadas (ou despesas com provisão para créditos de liquidação duvidosa).

Para a realização dos testes empíricos, é estruturado modelo de um estágio, tendo como proxy de gerenciamento a relação positiva esperada entre a parcela discricionária das despesas perdas estimadas de créditos (provisão para créditos de liquidação duvidosa) e o resultado antes das perdas estimadas (PCLD), dada a relação de resultado (desempenho das instituições financeiras) com as perdas estimadas despesas de provisão, relação esperada tanto para os bancos brasileiros quanto para os luso-espanhóis.

$$
\begin{aligned}
L L P_{i, t}=\beta_{0}+\beta_{i}+ & \beta_{1} L L a j_{i t}+\beta_{2} \Delta L O A N_{i, t}+\beta_{3} N P L_{i, t-1}+\beta_{4} \Delta N P L_{i, t}+\beta_{5} L L A_{i, t-1}+\beta_{6} I N T_{i, t}+\beta_{7} G D P_{t} \\
& +\beta_{8} L n A t_{i, t}+\varepsilon_{i t}
\end{aligned}
$$

Onde:

$L L P_{i, t}:$ despesas com provisão para créditos de liquidação duvidosa, do banco i, no período t, escalonado pelo total de ativos do início do período;

$L L a j_{i t}$ : resultado ajustado pelas despesas com provisões, do banco i, no período t, escalonado pelos ativos totais do início do período;

$\triangle L O A N_{i, t}$ : variação no valor do saldo da carteira de crédito, no período $\mathrm{t}$, do banco $\mathrm{i}$, escalonado pelo total de ativos do início do período;

$N P L_{i, t-1}$ : saldo dos créditos vencidos e não pagos, no período t-1, do banco i, escalonado pelo total de ativos do início do período;

$\triangle N P L_{i, t}$ : variação no valor dos empréstimos vencidos e não pagos, no período $t$, do banco i, escalonado pelo total de ativos do início do período;

$L L A_{i, t-1}$ : saldo acumulado da provisão para créditos de liquidação duvidosa, do banco i, no período t-1, escalonado pelo total de ativos do início do período;

$I N T_{i, t}$ : taxa de juros implícita média da carteira de crédito, do banco i, no período t, correspondente à razão entre as receitas de operações de créditos e o saldo médio da carteira;

$G D P_{t}$ : taxa de variação no Produto Interno Bruto do país, no período t;

$L n A t_{i, t}$ : logaritmo natural dos ativos totais, variável representativa do porte do banco i, no período $t$.

Com o objetivo de mitigar heteroscedasticidade, as variáveis $L L P, L L a j, \triangle L O A N, N P L$,

$\triangle N P L$ são escalonadas pelos ativos totais do início do período, conforme Kanagaretnam, Lim e Lobo (2010).

A inclusão da variável relativa à variação da carteira de crédito é justificada pela premissa de que quanto mais operações, maior o tamanho da provisão a ser constituída para 
cobrir perdas. A variável foi utilizada por Marcondes (2008) e Kanagaretnam, Lim e Lobo (2010).

Marcondes (2008) incorporou a taxa de juros implícita da carteira (INT) como variável explicativa da despesa com provisão, sendo prevista uma relação positiva, tendo em vista a premissa de que, para carteiras com maior taxa de juros, espera-se maior risco, o que deve se refletir em maior constituição de provisão para responder por potenciais perdas.

O nível de atividade da economia representado pela variável $\boldsymbol{G D P}$ é justificado com o argumento de que na constituição da provisão para créditos de liquidação duvidosa devem ser consideradas, entre outros aspectos, as condições econômicas do ambiente em que o banco opera, orientação do Federal Financial Institutions Examination Council (FFIEC) (2001).

A expectativa é que o sinal do resultado líquido ajustado, $L L_{a j}$ seja positivamente relacionado à variável dependente $(\boldsymbol{L} \boldsymbol{L} \boldsymbol{P})$, pois, em um cenário de gerenciamento de resultados, as instituições financeiras reduzem as despesas quando os resultados são baixos e aumentam as despesas quando os resultados são elevados. Não há um sinal esperado para a variável representativa do porte das instituições $(\boldsymbol{L n} \boldsymbol{A t})$.

\subsection{Amostra}

Para a composição da amostra foram coletados dados das trinta maiores instituições financeiras brasileiras e de 31 luso-espanholas. Foi aplicada como restrição à amostra, a ausência de dados que compõem os modelos econométricos aplicados na pesquisa. O Quadro 1 resume a amostra considerada no estudo.

Quadro 1: Composição da amostra

\begin{tabular}{|c|c|}
\hline País & Bancos \\
\hline Brasil & $\begin{array}{l}\text { ABC-BRASIL, ALFA, BANCOOB, BANESTES, BANRISUL, BB, BCO DA AMAZONIA } \\
\text { S.A., BCO DAYCOVAL S.A, BCO RABOBANK INTL BRASIL S.A, BCO TOKYO- } \\
\text { MITSUBISHI BM S.A., BIC, BMG, BNP PARIBAS, BRADESCO, BRB, BTG PACTUAL, } \\
\text { CAIXA ECONOMICA FEDERAL, CITIBANK, DEUTSCHE, HSBC, ITAU, JP } \\
\text { MORGANCHASE, MERCANTIL DO BRASIL, PANAMERICANO, PINE, SAFRA, } \\
\text { SANTANDER, SOCIETE GENERALE, VOTORANTIM, CRÉDIT AGRICOLE BRASIL } \\
\text { S.A. }\end{array}$ \\
\hline Portugal & $\begin{array}{l}\text { BANCO BPI, BANCO CARREGOSA, BANIF INV, BANIF SGPS, BBVA, BES, BESI, BIG, } \\
\text { BPN, CBI, CGD, CRÉDITO AGRÍCOLA, DEUTSCHE BANK, INVEST, MILLENNIUM } \\
\text { BCP, MONTEPIO, POPULAR, SANT CONSUMER, SANTANDER TOTTA SGPS. }\end{array}$ \\
\hline Espanha & $\begin{array}{l}\text { BANCA MARCH, BANCO BILBAO VIZCAYA ARGENTARIA, BANCO } \\
\text { COOPERATIVO ESPAÑOL, BANCO DE SABADELL, BANCO POPULAR ESPAÑOL, } \\
\text { BANCO SANTANDER, BANKINTER, BARCLAYS BANK, CAIXA BANK S.A., } \\
\text { DEUTSCHE BANK, S.A.E., DEXIA SABADELL, SANTANDER CONSUMER FINANCE }\end{array}$ \\
\hline
\end{tabular}

Para a amostra, foram consideradas as dezenove instituições financeiras portuguesas, sendo as treze maiores do país, ligadas à Associação Portuguesa de Bancos, e os Bancos Popular, Deutsche, BPN, BESI, BES e BANIF Invest, entre os mais representativos em total de ativo. E, ainda, as doze maiores instituições financeiras espanholas ligadas à Associação Espanhola de Bancos.

No caso das instituições brasileiras, a amostra foi constituída pelos trinta maiores bancos do país, conforme o relatório do BCB, por total de ativos, "50 Maiores Bancos e o Consolidado do Sistema Financeiro Nacional". Para fins de equilibrar as informações disponíveis para o modelo, foram substituídas as instituições Banco do Nordeste, Credit Suisse e Banco Cooperativo Sicredi, que, no relatório em 31 de dezembro de 2014, ocupavam as posições $12^{\circ}$, $15^{\circ}$ e $16^{\circ}$, respectivamente, pelas instituições Banco de Brasília, Banco Pine e Crédit Agricole 
do Brasil. Essa amostra tem grande representação do sistema financeiro brasileiro, ou seja, os 30 conglomerados que compõem a amostra têm participação de $96,72 \%$ no "Consolidado bancário I" e 79,23\% no Sistema Financeiro Nacional em total de ativo, deduzido a intermediação financeira.

\section{Análise dos Resultados}

\subsection{Testes Preliminares de Robustez}

Para garantir a robustez dos resultados empíricos, foram realizados os testes preliminares para assegurar a consistência dos achados. Para verificar a estacionariedade das séries, foram realizados os testes Dickey-Fuller Aumentado (ADF) e de Phillips-Perron (PP) de raízes unitárias, cujos resultados estão consolidados na Tabela 1. A hipótese nula do teste ADF e do teste PP é de que as séries analisadas têm raízes unitárias. As estatísticas calculadas pelo teste ADF e PP, respectivamente das amostras de Brasil e Portugal-Espanha, rejeitam a hipótese nula. Os resultados comprovam, estatisticamente, que as séries temporais analisadas são estacionárias, o que representa uma das condições para a robustez dos resultados.

Tabela 1: Teste ADF/PP de raízes unitárias

Portugal-Espanha

\begin{tabular}{lcc}
\hline Teste & Statistic & Prob. \\
\hline ADF - Fisher Chi-square & 1139.88 & 0.0000 \\
PP - Fisher Chi-square & 1295.50 & 0.0000 \\
\hline Brasil & & \\
\hline Teste & Statistic & Prob. \\
\hline ADF - Fisher Chi-square & 1200.11 & 0.0000 \\
PP - Fisher Chi-square & 1429.42 & 0.0000 \\
\hline
\end{tabular}

De forma a mitigar o risco de heterocedasticidade nos resíduos, as variáveis contábeis foram escalonadas na construção dos modelos. Além disso, foi utilizado o método de erros padrões seccionais SUR (PCSE), que estima parâmetros robustos assumindo a presença de heterocedasticidade nos resíduos.

Para verificar a existência de autocorrelação, que constitui violação a uma das hipóteses de um modelo clássico de regressão linear, foi realizado o teste de Durbin-Watson. A hipótese nula a ser testada é a de que os resíduos da regressão são autocorrelacionados. Os resultados demonstrados na Tabela 2 rejeitam a hipótese de autocorrelação. Pelos resultados, assume-se que os estimadores podem ser considerados como melhor estimador linear não enviesado.

Tabela 2: Teste Durbin Watson

\begin{tabular}{ccc}
\hline \multirow{2}{*}{ Teste } & \multicolumn{2}{c}{ Países } \\
\cline { 2 - 3 } & Brasil - Statistic & Portugal-Espanha - Statistic \\
\hline Durbin Watson - Statistic & 1,815883 & 1,767625 \\
\hline
\end{tabular}

Para mitigar o risco em relação à multicolinearidade, foi realizado o teste de Fator de Inflação de Variância (FIV), com os resultados consolidados na Tabela 3. Conforme Gujarati e Porter (2011), têm-se o comprometimento dos resultados em função da multicolinearidade 
quando o fator for maior que 10. Os resultados afastam os problemas relacionados à multicolinearidade.

Tabela 3: Teste VIF para risco de multicolinearidade

Portugal-Espanha

\begin{tabular}{lc}
\hline Teste VIF & FIVj \\
\hline Statistic & 1,515909 \\
Brasil & \\
\hline Teste VIF & FIVj \\
\hline Statistic & 2,662853
\end{tabular}

\subsection{Resultados dos Testes de Regressão}

Os resultados estimados pelo modelo (3.1) são consistentes com as premissas para testes da hipótese, fundamentados na análise dos testes estatísticos, dado o coeficiente de determinação R2, com poder explicativo de $62,45 \%$ e $34,03 \%$, respectivamente para amostra brasileira e luso-espanhola. Os resultados são evidenciados na Tabela 4.

Tabela 4: Estimação do Modelo (3.1) para identificação da prática de gerenciamento de resultados nos bancos brasileiros e luso-espanhóis

\begin{tabular}{|c|c|c|c|c|c|c|c|c|}
\hline LS - SUR & & & & & & & & \\
\hline$L L P_{i, t}=\beta_{0}+\beta_{i}+\beta_{1} L L a j_{i t}+$ & $\partial A N_{i, t}+\beta_{3} N$ & ${ }^{\mathrm{P}} L_{i, t-1}+\beta_{4} \Delta I$ & $\mathrm{~V} P L_{i, t}+f$ & & $A_{i, t-1}+\beta_{6} I \Lambda$ & $i, t+\beta_{7} G D P_{t}$ & ${ }_{8} L n A t_{i, t}+$ & $\varepsilon_{i t}$ \\
\hline Variável dependente: $L L P_{\mathrm{i}, \mathrm{t}}$ & & Brasil & & & Pol & tugal-Espanh: & & \\
\hline $\begin{array}{l}\text { Variable } \\
\end{array}$ & Coeficiente & Estatística & Prob. & & Coeficiente & Estatística t & Prob. & \\
\hline Panove & -372149.2 & -0.270410 & 0.7871 & & -2435380 & $-2,0331$ & 0.0432 & \\
\hline$\triangle L O A N_{i, t}$ & 0.0112 & 0.1932 & 0.8469 & & 0.1181 & 2,2977 & 0.0225 & $*$ \\
\hline$N P L_{i, t-1}$ & 0.2081 & 3,5782 & 0.0004 & * & 0.0583 & 2,1523 & 0.0325 & $*$ \\
\hline$\Delta N P L_{i, t}$ & 0.0129 & 0.9470 & 0.3445 & & 0.0129 & 1,4151 & 0.1584 & \\
\hline$L L A_{i, t-1}$ & -0.0252 & -0.5172 & 0.6054 & & -0.0313 & -0.8441 & 0.3996 & \\
\hline$I N T_{i, t}$ & 0.0241 & 2,7471 & 0.0064 & $*$ & -0.0014 & -0.0952 & 0.9243 & \\
\hline$G D P_{t}$ & 6814,3 & 0.4153 & 0.6782 & & 6334,9 & 1,4544 & 0.1472 & \\
\hline$L L_{a j}$ & 0.3518 & 6,2493 & 0.0000 & $*$ & 0.0742 & 2,9565 & 0.0034 & $*$ \\
\hline$L n A t_{i, t}$ & 0,0001 & -0.1010 & 0.9196 & & -0.0002 & -0.8916 & 0.3735 & \\
\hline R-quadrado & 0.6244 & & & & 0.3403 & & & \\
\hline R-quadrado ajustado & 0.5778 & & & & 0.2567 & & & \\
\hline Estatística F & 13,4067 & & & & 4,0719 & & & \\
\hline Prob(Estatística F) & 0.0000 & & & & 0.0000 & & & \\
\hline
\end{tabular}

Nível de significância a $10 \%(*), 5 \%(* *)$ e $1 \%(* * *)$

Onde: $L L P_{i, t}$ : despesas com provisão para créditos de liquidação duvidosa do banco i no período t, escalonado pelo total de ativos; $\triangle L O A N_{i, t}$ : variação no valor do saldo da carteira de crédito do período t-1 ao período $t$ do banco $\mathrm{i}$, escalonado pelo total de ativos; $N P L_{i, t-1}$ : saldo dos créditos vencidos e não pagos no período t-1 do banco $\mathrm{i}$, escalonado pelo total de ativos; $\triangle N P L_{i, t}$ : variação no valor dos empréstimos vencidos e não pagos do período t-1 a t do banco i, escalonado pelo total de ativos; $L L A_{i, t-1}$ : saldo acumulado da provisão para créditos de liquidação duvidosa do banco i no período t-1, escalonado pelo total de ativos; $I N T_{i, t}$ : taxa de juros implícita média da carteira de crédito do banco i no período $\mathrm{t}$, correspondente à razão entre as receitas de operações de créditos e o saldo médio da carteira; $G D P_{t}$ : taxa de variação no Produto Interno Bruto no período t; $L L_{a j}$ : resultado ajustado pelas despesas com provisões, escalonado pelos ativos totais; $L n A t_{i, t}$ : logaritmo natural dos ativos totais, variável representativa do porte das instituições financeiras.

O resultado da significância global do modelo, utilizando o teste (F) confirma que o modelo conjuntamente é significativo, rejeitando a hipótese nula de que os coeficientes 
estimados pela regressão são simultaneamente iguais a zero. Em outras palavras, as variações observadas nas despesas de provisão para créditos de liquidação duvidosa são decorrentes das alterações das variáveis explicativas e não ocorrem, somente, em função da variação no termo residual.

A análise do coeficiente de determinação, $\mathrm{R}^{2}$ ajustado $(0,577885)$ e $(0.256752)$, indica que as variáveis explanatórias utilizadas no modelo, explicam $57,79 \%$ e $25,68 \%$ das despesas de provisão para créditos de liquidação duvidosa constituídas do período.

Em relação à relação esperada e à significância das variáveis explicativas, essas são consolidadas no Quadro 2.

Quadro 2: Análise de relação esperada e resultados da estimação do modelo (3.1)

\begin{tabular}{|c|c|c|c|c|}
\hline \multirow{2}{*}{ Variável } & \multirow{2}{*}{ Comportamento Esperado } & \multicolumn{3}{|c|}{ Sinal dos Resultados } \\
\hline & & Esperado & Brasil & $\begin{array}{l}\text { Portugal- } \\
\text { Espanha }\end{array}$ \\
\hline$L L A_{\text {ajit }}$ & $\begin{array}{l}\text { Relação entre o resultado ajustado e as despesas com } \\
\text { provisão para crédito de liquidação duvidosa constitui a } \\
\text { proxy de gerenciamento de resultado, na qual a relação } \\
\text { positiva das despesas com resultado constitui o } \\
\text { comportamento de income smoothing nas instituições } \\
\text { financeiras. }\end{array}$ & $(+)$ & $(+)^{*}$ & $(+)^{*}$ \\
\hline$\triangle L O A N_{\mathrm{i}, \mathrm{t}}$ & $\begin{array}{l}\mathrm{O} \text { aumento na carteira de operações de créditos está } \\
\text { positivamente relacionado ao aumento das despesas de } \\
\text { provisão para créditos de liquidação duvidosa. }\end{array}$ & $(+)$ & $(+)$ & $(+)^{*}$ \\
\hline$N P L_{i, t-1}$ & $\begin{array}{l}\text { O nível de operações vencidas, do período anterior, deve } \\
\text { estar positivamente relacionado com a constituição da } \\
\text { provisão no período, pois a baixa qualidade dos créditos } \\
\text { motiva maiores níveis de provisão para créditos de } \\
\text { liquidação duvidosa. }\end{array}$ & $(+)$ & $(+)^{*}$ & $(+)^{*}$ \\
\hline$\triangle N P L_{\mathrm{i}, \mathrm{t}-1}$ & $\begin{array}{l}\text { Assim como no saldo da provisão anterior, a variação no } \\
\text { nível de operações vencidas deve estar positivamente } \\
\text { relacionada com a constituição da provisão no período, pois } \\
\text { a baixa qualidade dos créditos motiva maiores níveis de } \\
\text { provisão para créditos de liquidação duvidosa. }\end{array}$ & $(+)$ & $(+)$ & $(+)$ \\
\hline$L L A_{\mathrm{i}, \mathrm{t}-1}$ & $\begin{array}{l}\text { A provisão do período anterior pode ter influência na } \\
\text { constituição em novas, considerando o aumento da } \\
\text { deterioração, ou ainda pode relacionar-se uma redução } \\
\text { discricionária. }\end{array}$ & $(+/-)$ & $(-)$ & $(-)$ \\
\hline$I N T_{\mathrm{i}, \mathrm{t}}$ & $\begin{array}{l}\text { Espera-se sinal positivo relacionada à taxa média das } \\
\text { operações de créditos, em função do aumento da carteira e } \\
\text { seu risco/retorno. }\end{array}$ & $(+)$ & $(+)^{*}$ & $(-)$ \\
\hline$G D P_{\mathrm{t}}$ & $\begin{array}{l}\text { A variável de análise de atividade econômica, PIB espera- } \\
\text { se uma relação positiva quando do PIB positivo, haja vista } \\
\text { a relação de mais recursos disponíveis e mais operações. }\end{array}$ & $(+/-)$ & $(+)$ & $(+)$ \\
\hline$L n A t_{\mathrm{i}, \mathrm{t}}$ & $\begin{array}{l}\text { Logaritmo natural dos ativos totais, variável representativa } \\
\text { do porte das instituições financeiras. }\end{array}$ & $(+/-)$ & $(-)$ & $(-)$ \\
\hline
\end{tabular}

Onde: $(+)$ significa que a variável explicativa em questão se mostrou positivamente relacionada com a variável dependente; (-) significa que a variável explicativa em questão se mostrou negativamente relacionada variável dependente; $\left(^{*}\right)$ significa que há relação identificada pelo sinal, sendo estatisticamente significativa. 
A relação entre a parcela discricionária das despesas com perdas estimadas (ou provisão para crédito de liquidação duvidosa) ( $\left.L L P_{\mathrm{it}}\right)$ e o resultado ajustado ( $\left.L L A_{\mathrm{ajit}}\right)$, proxy de gerenciamento de resultado, confirmam que há relação positiva das despesas com lucro ou prejuízo, comportamento esse de income smoothing nas instituições financeiras, indicando, dessa forma, o gerenciamento de resultado nas instituições financeiras brasileiras e lusoespanholas. Assim, a variável constitui um elemento significativo nas estimativas para constituição das despesas com perdas estimadas das instituições financeiras, indicando existência de avaliação quanto ao nível de resultado existente para a constituição de perdas estimadas, comportamento esse de gerenciamento de resultados. Dessa forma, são corroboradas as hipóteses $\boldsymbol{H}_{1 \boldsymbol{A}}$ e $\boldsymbol{H}_{1 \boldsymbol{B}}$ de que há gerenciamento de resultados através das perdas estimadas (provisão para créditos de liquidação duvidosa) nas instituições financeiras brasileiras e lusoespanholas.

Os resultados confirmaram a relação positiva esperada entre a variação do saldo das operações de créditos $\left(\triangle L O A N_{\mathrm{i}, t}\right)$ e as despesas com perdas estimadas $\left(L L P_{\mathrm{it}}\right)$. Entretanto, se mostrou significativa apenas na amostra luso-espanhola e não na amostra brasileira, indicando haver poder explicativo do componente não discricionário na amostra luso-espanhola no período analisado.

Para as operações vencidas defasadas $\left(\mathrm{NPL}_{\mathrm{i}, \mathrm{t}-1}\right)$, os resultados da regressão mostram que o sinal do coeficiente é positivo, confirmando a expectativa e a característica de que os créditos deteriorados influenciam, de forma mais significativa, as provisões constituídas, conforme os normativos dos reguladores. Os resultados comprovam que a variável explica o comportamento do componente não discricionário das despesas com perdas estimadas (provisão para créditos de liquidação duvidosa). As variações das operações vencidas tiveram relação positiva $\left(\triangle N P L_{\mathrm{i}, \mathrm{t}}\right.$ 1), mas não foi significativa.

O saldo da provisão no período anterior $\left(L L A_{\mathrm{i}, \mathrm{t}-1}\right)$ teve relação negativa, não havendo relação esperada para a variável, não sendo significativa em ambas as amostras. A taxa média de juros $\left(I N T_{\mathrm{i}, t}\right)$, dada pela razão entre as receitas de operações de créditos e carteira de crédito, teve relação positiva na amostra brasileira e foi significativa, indicando que maiores níveis de remuneração das operações de crédito refletem maior nível de risco e mais provisões, diferentemente da amostra luso-espanhola, que teve relação negativa e não foi significativa. A relação da atividade econômica, dado pela variável (GDP), embora não significativa, teve relação positiva, indicando que o aumento da atividade tem por consequência efeito na carteira de operações de créditos e incremento nas despesas de perdas estimadas (provisão para créditos de liquidação duvidosa).

O resultado da variável representativa do porte das instituições financeiras ( $\left.\operatorname{LnAt} t_{i, t}\right)$ não foi significativo, indicando que não há influência no componente discricionário das despesas com perdas estimadas (ou provisão).

\section{Considerações Finais}

A pesquisa demonstrou que as estimadas contábeis relacionadas as perdas estimadas são utilizadas nas instituições financeiras para demonstrar uma perspectiva desejada pelos responsáveis pela apresentação dos relatórios contábeis dessas instituições. Foi possível confirmar que independente do ambiente regulatório e social inserido (Brasil, Portugal e Espanha) as instituições financeiras utilizaram o poder discricionário disponível aos gestores e preparadores das informações contábeis para mover o resultado em torno de uma representação parcial, evidenciando o gerenciamento de resultado por meio das perdas estimadas com operações de crédito.

O porte das instituições financeiras não indicou influencia na aplicação de estimativas com objetivo de gerenciar resultado, assim, os bancos alheios ao porte utilizaram as perdas 
estimadas com operações de crédito para gerenciar resultado. A pesquisa evidenciou a busca pela suavização dos resultados, que se caracteriza por amenizar a variação de resultado entre os períodos de avaliação de desempenho das instituições financeiras. A aplicação do gerenciamento de resultado nessa modalidade tem como característica avaliar o resultado antes da constituição das perdas estimadas com operações de crédito, para dessa forma, estimar perdas em níveis compatíveis com os objetivos dos responsáveis pelo reporte de desempenho.

Assim como em pesquisas anteriores como: de Shrieves e Dahl (2003) e Pinho e Martins (2009) constataram a existência de gerenciamento de resultado em instituições financeiras, nessa última em instituições financeiras portuguesas. Não obstante, a literatura mostra que as estimativas de perdas com operações de crédito também são utilizadas para gerenciar capital, visto o ambiente regulatório de monitoramento de risco.

Foi realizada uma abordagem de acumulações (accruals), as quais são consideradas bons elementos de predição. O modelo foi estruturado com base na literatura e com foco específico em instituições financeiras, sendo estruturado de acordo com a hipótese considerada para a pesquisa, tendo como proxy a relação do componente discricionário na formação das perdas estimadas, dada pela relação existente entre o lucro ajustado pelas despesas com perdas estimadas (ou provisões para crédito de liquidação duvidosa de operações de crédito, termo ainda utilizado no ambiente regulatório) e as respetivas despesas.

Os resultados, conforme as análises, mostraram uma relação entre o componente discricionário das despesas com perdas estimadas e o resultado ajustado, sendo estatisticamente significativo.

Sob a ótica da hipótese da pesquisa, considerando a proxy determinada, quando o resultado aumenta, os componentes discricionários das despesas com perdas estimativas também aumentam. E, igualmente, quando o resultado diminui, as despesas com perdas estimadas (provisões) são reduzidas. Esse cenário é válido para as instituições financeiras brasileiras e luso-espanholas, as quais demonstram significância e os mesmos sinais de coeficientes, indicando o gerenciamento de resultados. Os resultados indicam a aceitação da hipótese, tendo relação positiva entre as despesas com perdas estimadas (ou provisão para créditos de liquidação duvidosa) e os resultados das instituições financeiras brasileiras e lusoespanholas, assim sendo utilizada essas estimativas para gerenciar resultados.

A regressão foi realizada utilizando a metodologia de análise de dados em painel, método no qual os resultados levam em consideração as características individuais e os fatores atribuídos aos períodos sob análise. $\mathrm{O}$ método permitiu avaliar a relação positiva entre o componente discricionário das despesas com perdas estimadas e o resultado, e ainda, a relação entre essas duas variáveis no tempo.

Para mitigar o risco de heterocedasticidade, foi utilizado o método de erros padrões seccionais SUR (PCSE), que estima parâmetros robustos, tendo resultados semelhantes ao método ordinário comparativamente.

Como limitação da pesquisa, ressalta-se o período analisado (2009 a 2014) e a quantidade de instituições (30 brasileiras e 31 luso-espanholas) incluídas. A quantidade observações possíveis foi limitada para estabelecer equilíbrio entre as amostras dos sistemas financeiros brasileiro, português e espanhol pela restrição de dados no segundo sistema financeiro.

Os resultados da pesquisa foram consistentes com estudos anteriores e contribuíram para estabelecer um padrão de comparação entre os resultados das instituições financeiras brasileiras e luso-espanholas, tendo resultados consistentes com a expectativa metodológica, obtendo indicação positiva para aceitar a hipótese de gerenciamento de resultados por meio das perdas estimadas com operações de crédito.

A assunção de responsabilidade dos preparadores das informações contábeis na elaboração e aplicação de estimativas é especialmente sensível em situações, operações e 
negócios que possuem parte significativa do resultado relacionado a mensuração de transações que dependem de julgamento para serem mensurados.

A constante busca pela representação fidedigna oferece bons desafios a Ciência Contábil que initerruptamente busca dar respostas a contextos e riscos diferentes em negócios e operações de complexidades variadas. Contudo, a mensuração de resultado que envolve estimativas possui componente da percepção dos responsáveis pelo reporte de desempenho que possuem uma proporção de interesse ou entendimento que pode levar a representações diferentes por percepções diferentes.

\section{Referências}

AHMED, A. C.; TAKEDA, A. THOMAS, S. Bank loan loss provisions: a reexamination of capital management, earnings management and signaling effects. Journal of Accounting and Economics. v. 28, n. 1, p. 1-25, nov. 1999. DOI: http://dx.doi.org/10.1016/S01654101(99)00017-8

BEATTY, A. L.; CHAMBERLAIN, S. L.; MAGLIOLO, J. Managing financial reports of commercial banks: the influence of taxes, regulatory capital, and earnings. Journal of Accounting Research, v. 33, n. 2, p. 231-261, 1995. DOI: http://dx.doi.org/10.2307/2491487

BANCO DA ESPANHA - BDE. Circular n. 4, de 22 de dezembro de 2004. Normas de informação financeira pública. Disponível em:

http://www.bde.es/f/webbde/SJU/normativa/circulares/4.2004.pdf. Acesso em: $1^{\text {o }}$ out. 2015.

BENEISH, M. D. Earnings management: a perspective. SSRN, Abr. 2001. DOI:

http://dx.doi.org/10.2139/ssrn.269625

BEAVER, W. H.; ENGEL, E. E. Discretionary behavior with respect to allowances for loan losses and the behavior of security prices. Journal of Accounting and Economics, v. 22, ns. 1-3, p. 177-206, jan. 1996. DOI: http://dx.doi.org/10.1016/S0165-4101(96)00428-4

BURGSTAHLER, D., DICHEV I. Earnings management to avoid earnings decrease and losses. Journal of Accounting and Economics, v. 24, n. 1, p. 99-126, dez. 1997. DOI: http://dx.doi.org/10.1016/S0165-4101(97)00017-7

CHENG, Q.; WARFIELD, T. D.; YE, M. Equity incentives and earnings management: evidence from a regulated industry. CAAA Annual Conference 2009 Paper, SSRN, Jan. 2009. DOI: https://dx.doi.org/10.2139/ssrn.1326558

CONSELHO MONETÁRIO NACIONAL - CMN. Resolução n. 2.682, de 21 de dezembro de 1999. Dispõe sobre critérios de classificação das operações de crédito e regras para constituição de provisão para créditos de liquidação duvidosa. Brasília, 1999. Disponível em:http://www.bcb.gov.br/pre/normativos/busca/downloadNormativo.asp?arquivo=/Lists/Nor mativos/Attachments/44961/Res_2682_v2_P.pdf. Acesso em: 13 jun.2015.

CONSELHO MONETÁRIO NACIONAL - CMN. Resolução n. 3.786, de 24 de setembro de 2009. Dispõe sobre a elaboração e a divulgação de demonstrações financeiras consolidadas com base no padrão contábil internacional emitido pelo International Accounting Standards Board (IASB). Brasília, 2009. Disponível 
em:http://www.bcb.gov.br/pre/normativos/busca/downloadNormativo.asp?arquivo=/Lists/Nor mativos/Attachments/47513/Res_3786_v1_O.pdf. Acesso em: 13 jun. 2015.

COHEN, L. J.; CORNETT, M. M.; MARCUS, A. J.; TEHRANIAN, H. Bank earnings management and tail risk during the financial crisis. Journal of Money, Credit and Banking, v. 46, n. 1, p. 171-197, 2014. DOI: http://dx.doi.org/10.1111/jmcb.12101

DANTAS, J. A.; MEDEIROS, O. R.; LUSTOSA, P. R. B. O papel de variáveis econômicas e atributos da carteira na estimação das provisões discricionárias para perdas em operações de crédito nos bancos brasileiros. BBR - Brazilian Business Review, Vitória, v. 10, n. 4, p. 6995, out./dez. 2013. Disponível em: http://www.redalyc.org/articulo.oa?id=123029355003. Acesso em: $1^{\circ}$ out. 2015.

DECHOW, P. M.; HUTTON, A. P.; KIM, J. H.; SLOAN, R. G. Detecting earnings management: a new approach. Journal of Accounting Research. v. 50, n. 2, p. 275-334, maio 2012. DOI: 10.1111/j.1475-679X.2012.00449.x

DECHOW, P. M.; SKINNER, D. J. Earnings management: reconciling the views of accounting academics, practitioners and regulators. Accounting Horizons Sarasota. v. 14, n. 2, p. 235-250, jun. 2000. Disponível em:

http://faculty.chicagobooth.edu/douglas.skinner/research/papers/3358109.pdf. Acesso em: $1^{\circ}$ out. 2015.

FEDERAL FINANCIAL INSTITUTIONS EXAMINATION COUNCIL - FFIEC. Policy statement on allowance for loan and lease losses methodologies and documentation for banks and savings institutions. Federal Register. Jul. 2001. Disponível em:

http://www.federalreserve.gov/boarddocs/srletters/2006/SR0617a1.pdf. Acesso em: $1^{\mathrm{o}}$ out. 2015.

FERREIRA, Mariana do, NETO, Octavio Ribeiro de Mendonça, VASCONCELOS, Ana Lúcia Fontes de Souza. Impairment e PCLD: Análise da Convergência entre a IFRS 9 e Resolução 2.682/99 como Argumento para Pleitear, Junto ao Banco Central do Brasil, um Ajuste na Norma Nacional. EMPRAD, 2018. Disponível em:http://sistema.emprad.org.br/anais2018.php Acesso em : 18 mar. 2019.

FREYRE, G. Casa-grande \& senzala: formação da família brasileira sob o regime de economia patriarcal. 51. ed. São Paulo: Global, 2006.

GOULART, A. M. C. Gerenciamento de Resultados Contábeis em instituições

financeiras no Brasil. 2007. 219 f. Tese (Doutorado em Ciências Contábeis) - Faculdade de Economia, Administração e Contabilidade. Departamento de Contabilidade e Atuaria.

Universidade de São Paulo. São Paulo, 2007. Disponível em:http://www.teses.usp.br/teses/disponiveis/12/12136/tde-17032008-124153/pt-br.php. Acesso em: $1^{\circ}$ out. 2015.

GUJARATI, D. N; PORTER, D. C. Econometria básica. 5.ed. São Paulo: Saraiva, 2011.

HEALY, P. M. The effect of bonus schemes on accounting decisions. Journal of Accounting and Economics, v. 7, p. 85-107, 1985. DOI: http://dx.doi.org/10.1016/0165-4101(85)90029-1 
HEALY, P. M.; WHALEN, J. M. A review of the earnings management literature and its implications for standard setting. Accounting Horizons, v. 13, n. 4, p. 365-383, dez. 1999. Doi:_https://doi.org/10.2308/acch.1999.13.4.365

IMPRENSA NACIONAL. Casa da Moeda. Carta Circular n. 02/2014/DSP do Banco de Portugal. Critérios de referência - Mensuração da imparidade da carteira de crédito e respectivas divulgações. 2014. Disponível em:

http://www.bportugal.pt/sibap/application/app1/docs1/circulares/textos/2-2014-DSP.pdf. Acesso em: $1^{\circ}$ out. 2015.

KANAGARETNAM, K.; LOBO, G. J; MATHIEU, R. Managerial incentives for income smoothing through bank loan loss provision. 2001. DOI:

http://dx.doi.org/10.2139/ssrn.292674

KANAGARETNAM, K.; LIM, C. Y.; LOBO, G. J. Auditor reputation and earnings management: international evidence from the banking industry. Journal of Banking and Finance, v. 34, p. 2318-2327, jan. 2010. Disponível em:http://papers.ssrn.com/sol3/papers.cfm?abstract_id=1568866. Acesso em: 13 jun. 2015.

MARCONDES, D. A. Disciplina de mercado e as acumulações contábeis discricionárias. 2008. 150 f. Tese (Doutorado em Ciências Contábeis) - Departamento de Contabilidade e Atuária. Faculdade de Economia, Administração e Contabilidade. Universidade de São Paulo. São Paulo, 2008. Disponível em: http://www.teses.usp.br/teses/disponiveis/12/12136/tde19012009-111828/pt-br.php. Acesso em: $1^{\text {o }}$ out. 2015.

MARTINEZ, A. L. "Gerenciamento" dos Resultados Contábeis: Estudo Empírico das Companhias Abertas Brasileiras. 2001. Tese (Doutorado em Ciências Contábeis) Faculdade de Economia, Administração e Contabilidade. Departamento de Contabilidade e Atuária. Universidade de São Paulo. São Paulo, 2001. Disponível em: http://www.teses.usp.br/teses/disponiveis/12/12136/tde-14052002-110538/pt-br.php. Acesso em: $1^{\circ}$ out. 2015.

NIYAMA, J. K.; GOMES, A. L. O. Contabilidade de instituições financeiras. 4. ed. São Paulo: Atlas, 2012.

PINHO, P. S.; MARTINS, N. C. Determinants of portuguese bank's provisioning policies: discretionary behaviour of generic and specific allowances. Journal of Money, Investment and Banking, v. 10. 2009. Disponível em:

http://www.novasbe.unl.pt/pt/component/zoo/item/determinants-of-portuguese-banksprovisioning-policies-discretionary-behaviour-of-generic-and-specific-allowances. Acesso em: $1^{\circ}$ out. 2014.

RODRIGUES, A. Gerenciamento dos resultados contábeis através de receitas e despesas não operacionais: estudo empírico das Companhias "nível 1" - Bovespa. Sociedade, Contabilidade e Gestão, Rio de Janeiro, v. 2, n. 1, 2007. Disponível em: http://www.atena.org.br/revista/ojs-2.2.3-08/index.php/ufrj/article/viewFile/573/562. Acesso em: $1^{\text {o }}$ out. 2014.

SAYED, Samir; et al; Simulação dos Impactos da Alteração da Norma Internacional de Instrumentos Financeiros (IFRS 9) nos Maiores Bancos Brasileiros. Sociedade, 
Contabilidade e Gestão, Rio de Janeiro, v. 8, n. 1, 2013. Disponível em: https://core.ac.uk/download/pdf/26117391.pdf Acesso em: 17 mar. 2019.

SCHIPPER, K. Commentary on Earnings Management. Accounting Horizons, v. 3, n. 4, p. 91-102, dez. 1989. Disponível em:

http://connection.ebscohost.com/c/articles/4816073/commentary-earnings-management. Acesso em: $1^{\circ}$ out. 2014.

SILVA, K. O.; ROBLES JUNIOR, A. (2018) Provisão para créditos de liquidação duvidosa (PCLD) calculada conforme as normas do BACEN e IFRS: comparação. Cafi, v. 1 n. 1, p. 421. Disponível em: https://revistas.pucsp.br/index.php/CAFI/article/download/36949/25173. Acesso em: 17 mar. 2019.

SHRIEVES, R. E.; DAHL, D. Discretionary accounting and the behavior of japanese banks under financial duress. Journal of Banking and Finance, v. 27, n. 7, p. 1219-1243, jul. 2003. DOI: http://dx.doi.org/10.1016/S0378-4266(02)00252-2

SPOHR, Jonas. Essays on earnings management. Ekonomi Och Samhälle, n.153, 2005.

WONG, H. S. Equity incentives and earnings management: evidence from the banking industry. 2011. Dissertação (Mestrado em Ciências Contábeis) - Erasmus University in Rotterdam, 2011. Disponível em: https://www.google.com.br/url?sa=t\&rct=j\&q=\&esrc=s\&source=web\&cd=1\&ved=0ahUKEw iChua4sJvLAhWFgJAKHSoxAzAQFggcMAA\&url=http $\% 3 \mathrm{~A} \% 2 \mathrm{~F} \% 2 \mathrm{Fthesis.eur.nl} \% 2 \mathrm{Fpub}$ $\% 2 \mathrm{~F} 9042 \% 2 \mathrm{FM} 865$ -

Wong_196647.docx\&usg=AFQjCNEhJ5ry0of5yxjNTRlhj5AFPwKIJg\&sig2=VzGiDgm92bo txt505MrgeA\&bvm=bv.115339255,d.Y2I\&cad=rja. Acesso em: $1^{\circ}$ out. 2014.

ZENDERSKY, H. C. Gerenciamento de resultados em instituições financeiras no Brasil 2000 a 2004. 2005. Dissertação (Mestrado em Ciências Contábeis) - Programa Multiinstitucional e Inter-Regional de Pós-Graduação em Ciências Contábeis. Universidade de Brasília/Universidade Federal da Paraíba/Universidade Federal do Rio Grande do Norte. Brasília, 2005. Disponível em: http://cca.unb.br/images/dissert_mest/mest_dissert_076.pdf. Acesso em: $1^{\circ}$ out. 2014. 